\title{
Impact of Cytokines on Neural Stem/Progenitor Cell Fate
}

\author{
Jocelyn Breton ${ }^{1}$ and Yang Mao-Draayer ${ }^{2 *}$
}

${ }^{1}$ Middlebury College, Middlebury, VT 05753

${ }^{2}$ Department of Neurology, University of Vermont College of Medicine, Burlington, VT 05405

\begin{abstract}
Neural stem/progenitor cells (NSC/NPC) can be a powerful tool for the neural repair of the damaged brain. Many of the current challenges with stem cell therapies revolve around the problem that stem cells do not survive, migrate, proliferate and differentiate as much as hoped. Understanding the interaction between NPCs and the immune system is essential for the effective use of stem cell transplantation. Cytokines play an important role in determining the inflammatory microenvironment and have also been shown to have effects on the differentiation, proliferation, migration and survival of NPCs. The effects of cytokines on neural stem cell fate is more complex than once believed; the distinction between anti-inflammatory and pro- inflammatory cytokines is not straightforward and varies based on conditions such as cytokine concentration and area of transplantation. If their role is understood, cytokines could be used to improve the efficacy of stem cell treatments and enhance neural repair. In this review, we provide a comprehensive overview of the effects of various cytokines on NPC fate. The ultimate goal of this review is to demonstrate how manipulation of the CNS microenvironment through alteration of various cytokines can enhance the capacity of NPC differentiation, proliferation, and overall neural repair.
\end{abstract}

Keywords: Cytokines; Neural stem cells; Neurogenesis; Inflammation; Neural repair

Abbreviations: ADX: Adrenalectomized; CCR5: Chemokine Receptor Type 5; CNS: Central Nervous System; CREB: Camp Response Element-Binding; CXCR4: Chemokine Receptor Type 4; DG: Dentate Gyrus; EAE: Experimental Autoimmune Encephalomyelitis; GFAP: Glial Fibrillary Acidic Protein; IFN: Interferon; IGF-1: Insulinlike Growth Factor 1; IL: Interleukin; JAK: Janus Kinase; LFA-1: Lymphocyte Function-associated Antigen 1; LPS: Lipopolysaccharide; MAP-2: Microtubule-Associated Protein-2; MAPK: Mitogen-Activated Protein Kinase; MHC: Major Histocompatibility Complex; MS: Multiple Sclerosis; NfkB: Nuclear Factor Kappa-light-chain-enhancer of activated B cells; NPC: Neural Progenitor Cell; SGZ: Subgranular Zone; STAT: Signal Transducers and Activators of Transcription; SVZ: Subventricular Zone; TGF: Transforming Growth Factor; TNF: Tumor Necrosis Factor

\section{Introduction}

Neural stem cell transplantation has been proposed as a therapy for a number of neurodegenerative disorders, including Alzheimer's, Parkinson's, and some aspects of Multiple Sclerosis (MS) [1]. The ultimate goal of such therapies is to enhance neurogenesis in damaged areas. Neurogenesis is the process by which new neurons are formed from neural progenitor cells. This process occurs in two main areas of the adult brain: the subventricular zone (SVZ) of the lateral ventricles and the subgranular zone (SGZ) of the dentate gyrus in the hippocampus [2]. Both transplanted and endogenously generated neural stem cells may be vital to CNS repair [3].

The understanding of complex neural-immune interactions, once thought limited to disorders such as MS, is essential to the improvement of stem cell therapies. Inflammation in the CNS strongly affects stem cell therapies [3]. NPC transplantation itself elicits an inflammatory response, which in turn influences NPC fate and the success or failure of a transplant [1]. The niche in which NPCs reside determines NPC fate, and this niche is partially controlled by components of the immune system. Our group has demonstrated bi-directional interactions between NPCs and subgroups of T-cells (Th1, Th2, Th17) [4]. One key set of molecules that define this niche are cytokines: small secreted proteins that modulate communication between immune cells and between immune and NPC cells [5]. Proinflammatory cytokines have neuroprotective effects in some contexts, and damaging effects in others [6]. However, it seems a balance between pro- and anti-inflammatory cytokines must be met in order for repair to occur [7]. Several other excellent reviews have also evaluated the role that neuroinflammation has on NPCs [3,8-10]. A better understanding of interactions between the immune system and NPCs is important for improving stem cell transplantation for all neurodegenerative disorders. With such knowledge, immunomodulatory factors such as cytokines could be manipulated in order to enhance neurogenesis and neural repair. Here, we provide a comprehensive overview of the effects of studied cytokines on NPC fate (Table 1).

\section{Pro-inflammatory cytokines}

Interleukin-1-beta (IL-1 $\beta$ ): Interleukin-1-beta is an important pro-inflammatory cytokine and its receptor, IL-1RI, is expressed on neural progenitor cells (NPCs) in the SGZ but not in the SVZ $[11,12]$. Specifically, IL-1 $\beta$ is up-regulated in response to stress and injury [12]. IL-1 $\beta$ inhibits the neurogenesis of NPCs by influencing their proliferation and differentiation. Studies found decreased proliferation of both embryonic NPCs in vitro and adult NPCs in vitro and in vivo $[12,13]$ Wang et al. [13] also discovered that IL-1 $\beta$ decreased survival of embryonic NPCs but increased GFAP expression, suggesting greater differentiation toward an astrocyte lineage rather than a neuronal lineage. No effect on migration was seen. In regards to adult NPCs, there appears to be no effect of IL- $1 \beta$ on either survival or differentiation

*Corresponding author: Yang Mao-Draayer, Department of Neurology, University of Vermont College of Medicine, Burlington, VT 05405, Tel: 802-6568984; Fax: 802-656-4674; E-mail: yang.mao-draayer@vtmednet.org

Received August 15, 2011; Accepted November 01, 2011; Published November 18, 2011

Citation: Breton J, Mao-Draayer Y (2011) Impact of Cytokines on Neural Stem/ Progenitor Cell Fate. J Neurol Neurophysiol S4. doi:10.4172/2155-9562.S4-001

Copyright: (c) 2011 Breton J, et al. This is an open-access article distributed under the terms of the Creative Commons Attribution License, which permits unrestricted use, distribution, and reproduction in any medium, provided the original author and source are credited. 
Citation: Breton J, Mao-Draayer Y (2011) Impact of Cytokines on Neural Stem/Progenitor Cell Fate. J Neurol Neurophysiol S4. doi:10.4172/21559562.S4-001

Page 2 of 7

\begin{tabular}{|c|c|c|c|c|c|c|c|c|}
\hline Cytokine & \begin{tabular}{|c|} 
Type of \\
Progenitor Cell
\end{tabular} & $\begin{array}{l}\text { Experimental } \\
\text { model used }\end{array}$ & $\begin{array}{c}\text { Role in } \\
\text { proliferation }\end{array}$ & Role in differentiation & $\begin{array}{l}\text { Role in } \\
\text { survival }\end{array}$ & $\begin{array}{l}\text { Role in } \\
\text { migration }\end{array}$ & Notes & Reference \\
\hline \multicolumn{9}{|c|}{ Pro-Inflammatory } \\
\hline \multirow[t]{4}{*}{ IL-1 $\beta$} & eNPC, rat & in vitro & decreased & $\begin{array}{c}\text { increased astrocyte } \\
\text { lineage }\end{array}$ & decreased & no effect & $\begin{array}{l}\text { SAPK/JNK } \\
\text { pathway }\end{array}$ & [13] \\
\hline & aNPC, rat, SGZ & in vitro & decreased & ND & no effect & ND & $\begin{array}{c}\text { Receptor } \\
\text { subtype IL-1R1 }\end{array}$ & {$[12]$} \\
\hline & & in vivo & decreased & ND & no effect & ND & & \\
\hline & & in vitro & ND & no effect & ND & ND & & {$[14]$} \\
\hline IL-1a & eNPC, mouse & in vitro & ND & $\begin{array}{c}\text { increased astrocyte } \\
\text { lineage }\end{array}$ & no effect & ND & & [17] \\
\hline \multirow[t]{5}{*}{ IL-6 } & eNPC, mouse & in vitro & ND & increased neurogenesis & ND & ND & MAPK/CREB & [22] \\
\hline & & & & increased gliogenesis & & & $\begin{array}{l}\text { STAT3 H-IL-6 } \\
\text { only }\end{array}$ & \\
\hline & $\begin{array}{l}\text { aNPC, human, } \\
\text { SVZ \& SGZ }\end{array}$ & in vitro & ND & increased & ND & ND & $\begin{array}{c}\text { no effect on } \mathrm{MHC} \\
\text { expression }\end{array}$ & [21] \\
\hline & $\begin{array}{c}\text { pnNPC, mouse, } \\
\text { SGZ }\end{array}$ & in vivo & decreased & decreased & decreased & no effect & & [20] \\
\hline & aNPC, rat, SGZ & in vitro & decreased & decreased & decreased & ND & & [14] \\
\hline \multirow[t]{9}{*}{ TNF- $\alpha$} & eNPC, rat & in vitro & decreased & ND & decreased & ND & & [31] \\
\hline & eNPC, rat & in vitro & ND & increased & decreased & ND & $\begin{array}{l}\text { via activated } \\
\text { microglia }\end{array}$ & [32] \\
\hline & $\begin{array}{c}\text { aNPC, mouse, } \\
\text { SVZ }\end{array}$ & in vitro & no effect & no effect & decreased & ND & & [30] \\
\hline & $\begin{array}{c}\text { aNPC, rats, } \\
\text { SVZ }\end{array}$ & in vitro & increased & no effect & decrease & ND & $\mathrm{NfKB}$ & [29] \\
\hline & aNPC, rat, SVZ & in vivo & increased & ND & no effect & ND & & [28] \\
\hline & $\begin{array}{l}\text { pnNPC, rat, } \\
\text { SVZ }\end{array}$ & in vitro & decreased & no effect & increased & increased & blocked IFN-Y & [11] \\
\hline & $\begin{array}{c}\text { aNPC, mouse, } \\
\text { SGZ }\end{array}$ & in vivo & $\begin{array}{l}\text { decreased } \\
\text { (TNFRI) }\end{array}$ & decreased (TNFR1) & $\begin{array}{l}\text { increased } \\
\text { (TNFRII) }\end{array}$ & ND & $\begin{array}{c}\text { differed based on } \\
\text { receptor }\end{array}$ & [27] \\
\hline & aNPC, rat, SGZ & in vitro & ND & decreased & ND & ND & & [14] \\
\hline & $\begin{array}{l}\text { aNPC, human, } \\
\text { SVZ \& SGZ }\end{array}$ & in vitro & ND & increased gliogenesis & ND & ND & $\begin{array}{l}\text { increased } \mathrm{MHC} \\
\text { expression }\end{array}$ & [21] \\
\hline IL-18 & eNPC, rat & in vitro & ND & increased & decreased & ND & & [32] \\
\hline \multirow[t]{2}{*}{ IL-2 } & eNPC, rat & in vitro & ND & ND & no effect & ND & & [31] \\
\hline & pnNPC, rat & in vitro & ND & increased & no effect & ND & & [23] \\
\hline \multirow[t]{6}{*}{ IFN-y } & eNPC, rat & in vitro & decreased & ND & decreased & ND & & [39] \\
\hline & $\begin{array}{l}\text { pnNPC, rat, } \\
\text { SVZ }\end{array}$ & in vitro & decreased & no effect & decreased & increased & & [11] \\
\hline & $\begin{array}{c}\text { aNPC, mouse, } \\
\text { SVZ }\end{array}$ & in vitro & no effect & increased & ND & ND & $\begin{array}{l}\text { via activated } \\
\text { microglia } \\
\text { low levels }\end{array}$ & [37] \\
\hline & $\begin{array}{c}\text { aNPC, mouse, } \\
\text { SVZ }\end{array}$ & in vitro & decreased & increased & no effect & ND & $\begin{array}{c}\text { increased neurite } \\
\text { branching }\end{array}$ & [30] \\
\hline & $\begin{array}{l}\text { aNPC, human, } \\
\text { SVZ \& SGZ }\end{array}$ & in vitro & ND & increased & ND & ND & $\begin{array}{c}\text { increased } \mathrm{MHC} \\
\text { expression }\end{array}$ & [21] \\
\hline & aNPC, rat, SGZ & in vitro & ND & no effect & ND & ND & & {$[14]$} \\
\hline \multicolumn{9}{|c|}{ Anti-inflammatory } \\
\hline \multirow[t]{2}{*}{ IL-10 } & $\begin{array}{c}\text { aNPC, mouse, } \\
\text { SVZ }\end{array}$ & in vitro & ND & ND & ND & increased & $\begin{array}{l}\text { upregulated } \\
\text { chemokine } \\
\text { receptors }\end{array}$ & [45] \\
\hline & $\begin{array}{c}\text { aNPC, mouse, } \\
\text { SVZ }\end{array}$ & in vivo & ND & $\begin{array}{c}\text { increased neurogenesis } \\
\text { increased } \\
\text { oligodendrogenesis }\end{array}$ & increased & ND & & [42] \\
\hline \multirow[t]{2}{*}{ IL-4 } & $\begin{array}{c}\text { aNPC, mouse, } \\
\text { SVZ }\end{array}$ & in vitro & no effect & $\begin{array}{c}\text { increased } \\
\text { oligodendrogenesis }\end{array}$ & ND & ND & $\begin{array}{l}\text { via activated } \\
\text { microglia }\end{array}$ & [37] \\
\hline & $\begin{array}{c}\text { aNPC, mouse, } \\
\text { SVZ }\end{array}$ & in vitro & ND & ND & ND & increased & $\begin{array}{l}\text { upregulated } \\
\text { chemokine } \\
\text { receptors }\end{array}$ & [45] \\
\hline \multirow[t]{2}{*}{ TGF- $\beta$} & $\begin{array}{c}\text { aNPC, mouse, } \\
\text { SVZ }\end{array}$ & in vivo & decreased & no effect & increased & ND & & [51] \\
\hline & & in vitro & decreased & no effect & increased & ND & & \\
\hline
\end{tabular}




\begin{tabular}{|c|c|c|c|c|c|c|c|c|}
\hline & aNPC, rat, SGZ & in vivo & decreased & increased & ND & ND & & {$[48]$} \\
\hline & & in vitro & decreased & increased & ND & ND & & \\
\hline & aNPC, rat, SGZ & in vitro & decreased & ND & no effect & ND & & {$[47]$} \\
\hline & $\begin{array}{c}\text { aNPC, mouse, } \\
\text { SGZ }\end{array}$ & in vivo & decreased & ND & decreased & ND & & \\
\hline & $\begin{array}{c}\text { aNPC, mouse, } \\
\text { SGZ }\end{array}$ & in vivo & decreased & no effect & increased & ND & & {$[51]$} \\
\hline & $\begin{array}{c}\text { aNPC, mouse, } \\
\text { SGZ }\end{array}$ & in vivo & increased & increased & increased & ND & & {$[52]$} \\
\hline \multicolumn{9}{|c|}{ Unclassified } \\
\hline \multirow[t]{2}{*}{ IL-15 } & pnNPC, rat & in vitro & no effect & decreased & no effect & ND & MAP-2/STAT-3 & {$[56]$} \\
\hline & $\begin{array}{c}\text { aNPC, mouse, } \\
\text { SVZ }\end{array}$ & in vitro & increased & decreased & no effect & ND & & {$[57]$} \\
\hline \multirow[t]{2}{*}{ IL-7 } & eNPC, human & in vitro & ND & increased neurogenesis & ND & increased & & {$[60]$} \\
\hline & aNPC, human & & & increased gliogenesis & & & & \\
\hline
\end{tabular}

IL, interleukin; TNF- $\alpha$, tumor necrosis factor-alpha; TGF- $\beta$, transforming growth factor-beta; NPC, neural progenitor cell; SGZ, subgranular zone; SVZ, subventricular zone; ND, no data; eNPC, embryonic NPC; pnNPC, postnatal NPC; aNPC, adult NPC

Table 1: Cytokine effects on NPC fate

$[12,14]$. Although these results suggest a detrimental effect on NPCs, modest concentrations of IL-1 $\beta$ have been shown to be beneficial for the survival of primary neurons in vitro [15]. Despite potential positive effects on survival, overall decreased neurogenesis is observed. In order to improve stem cell treatments, IL- $1 \beta$ should be reduced under disease circumstances.

Interleukin-1-alpha (IL-1a): The effect of interleukin-1 alpha on neural stem/progenitor cell fate is often ignored in favor of the betterstudied IL-1 $\beta$. However, LPS stimulation increases the alpha form of IL-1 more than the beta form [16]. Ajmone-Cat et al. [17] demonstrated a new role for IL-1 $\alpha$ as a modulator of NPC fate. At low levels, IL-1a has a progliogenic effect on NPCs. Similar to IL- $1 \beta$, in vitro studies demonstrate that IL- $1 \alpha$ enhances differentiation into the astrocytic lineage in embryonic NPCs, but has no affect on neuronal lineage or cell survival [17]. When IL-1 $a$ was depleted from activated microglia media, neuronal differentiation was slightly increased, indicating that IL-1 $\alpha$ may contribute to the anti-neurogenic effect that activated microglia have on NPCs [14]. Further studies will need to elucidate the exact role of IL-1 $\alpha$ on neurogenesis, looking at effects on proliferation as well as on adult NPCs.

Interleukin-6 (IL-6): Interleukin-6 belongs to the neuropoietic cytokine family, all of which signal through the transmembrane gp130 receptor and act upon the JAK/STAT pathway [3]. Adult NPCs do not express the IL- 6 receptor [18]; however, IL- 6 can first bind to the soluble form of IL-6R and then bind directly to the gp130 receptor expressed on NPCs, enabling the cytokine to act [19].

IL-6 decreases the proliferation and survival of NPCs [14,20]. However, there are conflicting data on the role of IL-6 in NPC differentiation. Vallières et al. [20] found that IL-6 decreases differentiation of NPCs in the subgranular zone (SGZ) of the hippocampus. However, under some conditions differentiation is increased. IL- 6 actually stimulates differentiation in human fetal NPC taken from both the striatum and hippocampus [21]. Similarly, highly active IL-6 (H-IL-6) increases differentiation of embryonic stem cells into glutamate responsive neurons and two astroglia cell types via the MAPK/CREB pathway [22]. H-IL-6 also enhances gliogenesis through the STAT-3 pathway [22]. In accordance with these findings, IL-6 promotes neurite elongation of embryonic NPCs in the SGZ [23]. Additionally, IL-6 can promote differentiation of NPCs at low concentrations [24]. A potential explanation of these beneficial effects could be found via the interaction of IL- 6 with other cytokines produced in the inflammatory response. IL- 6 reduces pro-inflammatory TNF- $\alpha$ and IL-1 production and helps circulate IL-1 receptor antagonist [25]. Further studies are needed to determine when IL-6 is detrimental or beneficial to the differentiation of NPCs.

These conflicting data could also be explained by the finding that IL-6 expression varies as a function of age, indicating that the role IL-6 plays may change over time [20]. Initially, IL-6 may help embryonic NPCs differentiate, but later, long-term expression is detrimental. Like many cytokines, different concentrations and contexts will lead to distinct physiological effects [26]. Even with a beneficial role in differentiation, if IL-6 is chronically over-expressed, reduced neurogenesis ensues [19]. These results suggest that IL-6 levels should be reduced for effective neural stem cell treatments.

Tumor Necrosis Factor-alpha (TNF- $\alpha)$ : TNF- $\alpha$ is often regarded as a classic pro-inflammatory cytokine. However, current findings show conflicting effects of TNF- $\alpha$ on NPC fate. TNF- $\alpha$ acts on two different receptor subtypes, TNF-RI and TNF-RII. TNF-R1 generally mediates pro-inflammatory effects, while TNF-RII mediates neuroprotective effects [27]. Binding to TNF- RI decreases both proliferation and differentiation, while binding to TNF-RII increases survival [27]. Both receptor subtypes are found in the DG and in the SVZ [27].

The detrimental or beneficial effects of TNF- $\alpha$ depend on the amount of the cytokine, the receptor subtype activated and the area of the brain in which NPCs are found. Engagement of receptor TNF-RI in the SGZ inhibits adult NPC ability to proliferate and differentiate $[14,27]$. However, the effects of TNF- $\alpha$ in the SVZ are less clear. Several studies found increased proliferation but decreased survival of adult NPCs, with no effect on differentiation [28-30]. However, Ben-Hur et al [11] found the opposite; TNF- $\alpha$ decreased proliferation and, through interferon-gamma antagonism, increased survival of adult NPCs. Additionally, TNF- $\alpha$ promoted migration of NPCs $[11,28]$. In contrast to the adult NPC findings stated above, embryonic NPCs showed increased differentiation but reduced proliferation and survival $[31,32]$.

TNF- $\alpha$ has recently been demonstrated to activate the NfאB pathway in NPCs in vitro, thereby increasing both proliferation and apoptosis [29]. TNF-RI plays a role in NfKB activation supporting the finding that TNF-RI mediates proliferation [29]. The NfkB signalling pathway would explain why increased proliferation was observed but would 
contrast with the in vivo data indicating that TNF-RI is detrimental for proliferation. Greater cell turnover does not always indicate increased cell number. In vivo, other factors may be involved in the suppression of NPC proliferation and in the induction of apoptosis. Furthermore, the role of TNF- $a$ may change over time, explaining some of the varied results. For example, TNF- $\alpha$ is toxic when NPCs are proliferating [30]. On the whole, animals lacking both TNF- $\alpha$ receptors show exacerbated neuronal damage, suggesting a neuroprotective effect for TNF- $\alpha$ [33]. Therefore, inhibiting TNF-RI could be helpful in improving stem cell therapies although ideally, activation of the $\mathrm{Nf \kappa B}$ pathway should be maintained.

Interleukin-18 (IL-18): Interleukin-18 is among most recently discovered pro-inflammatory cytokine and a relative of TNF- $\alpha$ [32]. As of yet, few studies have been conducted demonstrating the effects of IL-18 on NPC fate. IL-18 decreases the number of differentiating embryonic NPCs in vitro in a dose and time dependent manner [32]. Further studies will need to elucidate the role of IL-18 on NPCs under varying conditions. However, based on these preliminary data, reducing the levels of IL-18 may be beneficial for neural stem cell therapies.

Interleukin-2 (IL-2): Although interleukin-2 has been considered a classic pro-inflammatory cytokine, its exact role in NPC fate remains elusive. Postnatal NPCs treated with IL-2 increased differentiation; both elongation and branching of neurites increased [23]. No effect on survival was noted $[23,31]$. On the contrary, several studies have shown that IL-2 knockouts have increased neurogenesis as well as increased IL-15 levels [34]. IL-2 and IL-15 share the same receptor subunits in the hippocampus [34]. Overall, IL-2 may have pro-neurogenic effects under some conditions but not others. The beneficial effects of IL-2 on neurogenesis may come from its modulatory role in the production of other cytokines; IL-2 is important for activation induced cell death [35]; these dying cells go on to produce their own cytokines [36]. Further studies will need to be conducted to clarify the mechanism by which IL-2 functions, as well as conditions under which IL-2 is beneficial or detrimental to NPC fate.

Interferon-gamma (IFN- $\gamma)$ : Interferon-gamma is also regarded as a pro-inflammatory cytokine, detrimental to neurogenesis. However, new data demonstrate that low levels of IFN- $\gamma$ activate microglia, and that this, contrary to previous beliefs, can be beneficial for the development of NPCs $[37,38]$. IFN- $\gamma$ activated microglia aid neurogenesis [18] by promoting differentiation, migration and neurite outgrowth, yet inhibiting proliferation and survival $[11,30,39,40]$. However it should be noted that data are again mixed: in one study, IFN- $\gamma$ increased survival of embryonic NPCs, contrasting with previous results [30]. In human cell lines, IFN- $\gamma$ increased differentiation and up-regulated major histocompatibility complex (MHC) expression on NPCs [21]. Up-regulation of MHC expression causes transplanted stem cells to be more susceptible to graft rejection [41]. In regards to stem cell therapies, IFN- $\gamma$ should be suppressed if levels are high, but low levels could be beneficial to neural repair and neurogenesis.

\section{Anti-inflammatory cytokines}

Interleukin-10 (IL-10): The anti-inflammatory effects of interleukin-10 have only recently been studied. In vivo, IL-10 increases both neurogenesis and oligodendogenesis [42]. More NPCs survived and differentiated in mice engineered to over express IL-10 when the MS model EAE was induced [42]. IL-10 also increased survival of OPCs [43] and increased migration of NPCs via up-regulation of surface adhesion molecules/chemokine receptors LFA-1, CXCR4 and CCR5 [45]. IL-10 has been shown to inhibit the release of pro-inflammatory cytokines such as IFN- $\gamma$ and IL-17 [42]. In vivo studies demonstrate increased remeylination in EAE mice, indicating that IL-10 could play an important role in neural repair for disorders such as MS [44]. Further in vitro studies could identify the mechanism by which IL-10 functions.

Interleukin-4 (IL-4): Interleukin-4 plays a similar neuroprotective role as IL-10, although to a lesser extent. IL-4 has no effect on the proliferation or survival of NPCs. However, IL-4 induces microglia to secrete more insulin-growth like factor 1 (IGF-1) and less TNF- $\alpha$ [37], establishing a neuroprotective microglial phenotype. Additionally, IL-4 up-regulates the same surface adhesion molecules/chemokine receptors as IL-10, increasing migration of NPCs [45]. IL-4 levels decrease with age and are accompanied by increased levels of IL-1 and decreased survival of hippocampal cells [46]. Similar to IL-10, IL-4 can down-regulate pro-inflammatory cytokines: in vivo, IL-4 directly inhibits IL-1 cytokine and receptor synthesis [46]. IL-4 could be upregulated in order to promote neural repair and enhance neural stem cell treatments.

Transforming Growth Factor-beta (TGF- $\beta$ ): Transforming growth factor-beta is a well-studied anti-inflammatory cytokine that increases rapidly after injury and with age [47]. However, the effects of TGF- $\beta$ are highly context dependent.

In the SGZ, TGF- $\beta$ causes a trend toward decreased proliferation and increased differentiation of NPCs, enhancing neurogenesis $[9,48]$. Adrenalectomy has previously been shown to increase neurogenesis [49]. Reduction of glucocorticoids released by the adrenal gland both increases NPC proliferation and also causes cell death of mature dentate granule cells [50]. Such cell death may be necessary for modification of the neurogenic niche. In adrenalectomized (ADX) animals, increasing levels of TGF- $\beta$ have been correlated with the amount of neurogenesis [48]. However if TGF- $\beta$ was blocked in ADX animals, neurogenesis was impaired. In contrast, Wachs [51] found that TGF- $\beta$ inhibited proliferation and overall neurogenesis in the dentate gyrus by arresting NPCs in the G0/1 phase of the cell cycle. No effect on differentiation was seen. The chronic overproduction of TGF- $\beta$ also blocks the production of new neurons [47]. Both inhibited proliferation and NPC survival were seen in aging mice treated with TGF- $\beta$, concluding that TGF- $\beta$ may need to be reduced if stem cell therapies are to be used in the aged brain.

In the SVZ in vivo studies treating ischemic damage with TGF- $\beta$ increases the proliferation, differentiation, survival, and migration of NPCs [52]. On the other hand, in vitro studies have demonstrated a decrease in NPC proliferation and no effect on differentiation [51]. It is likely that the in vivo effects of TGF- $\beta$ are mediated by other factors. TGF- $\beta$ is up-regulated by activated microglia [51] and may interact with other cytokines secreted, complicating its effect on NPC fate. One possible explanation for the beneficial in vivo effects is the inhibition TGF- $\beta$ exerts on the production of pro-inflammatory cytokines IL-1, TNF- $\alpha$ and IFN- $\gamma$, among others [53].

As a whole, animals that lack TGF- $\beta$ don't survive into adulthood; the majority of neuronal cell death occurs at day 1 , indicating that TGF- $\beta$ is necessary for development [54]. It may be the case that TGF- $\beta$ is beneficial initially but has deleterious long-term effects [55]. The role of TGF- $\beta$ in different disease models remains to be elucidated. It is possible that TGF- $\beta$ can help with neural repair and improve neural stem cell therapies under the right contexts. 


\section{Unclassified cytokines}

Interleukin-15(IL-15): Interleukin-15 is a recently studied cytokine whose receptor is found in differentiating neurons but not in astrocyte or oligodendroctye lineages [56]. IL-15 decreases differentiation and has no effect on the survival of NPCs. IL-15 also increases proliferation in adult NPCs, but not in postnatal NPCs [56,57]. Neurite outgrowth was decreased via reduced MAP-2 expression [56]. MAP-2 is an important structural protein that supports growing neurites [58]. It was also observed that IL-2 and IL-15 counter each other; IL-2 promoted neurite expression whereas IL-15 reduced expression. One possible explanation for the detrimental effects of IL-15 on NPCs could be due to the fact that IL-15 counters the beneficial effects of TGF- $\beta$ [59].

A beneficial role of IL-15 has also been noted in several studies [57]. IL-15 increased proliferation but decreased differentiation in adult NPCs [57]. IL-15 deficient mice had reduced proliferation and overall decreased neurogenesis, indicating that IL-15 is necessary for proper neurogenesis [57]. The conditions under which IL-15 is beneficial or detrimental to NPC fate remain to be fully described.

Interleukin-7 (IL-7): Interleukin-7 has not yet been classified as anti-or pro-inflammatory, but in a recent study by Moors et al. [60] fetal and adult human NPCs showed both increased neurogenesis and gliogenesis, as well as increased survival. No effect on migration was observed. Different splice variants of IL-7 had varying potencies on differentiation, with IL-7c as the most potent [60]. Future studies may wish to look into IL-7 as a potential neuroprotective anti-inflammatory cytokine. The specific mechanism by which IL-7 functions remains be determined. Overall, IL-7 is shown to act as a neural growth and differentiation factor both in vitro and in vivo $[60,61]$.

\section{Discussion}

Pro-inflammatory cytokines generally inhibit neurogenesis while anti-inflammatory cyokines enhance neurogenesis. A third category of unclassified cytokines can have pleiotropic effects, although their complete role in neurogenesis remains to be defined. Classic proinflammatory cytokines such as IL-1 $\beta$, IL- 6 and IL-18 are detrimental to NPC fate when over-expressed in disease states and should therefore be reduced in order to enhance stem cell transplantation. However, the contribution of certain cytokines is highly context dependent. The effects of TNF-a on NPC fate vary based upon the receptor subtype activated [27]. In vivo antineurogenic effects of TNF-RI should be inhibited to support neural repair. Additionally, microglia can promote either a pro-inflammatory or an anti-inflammatory response depending on the activating cytokine and their concentrations [9]. IFN- $\gamma$ at low doses promotes a neuroprotective phenotype of microglia, beneficial for neural repair [37]. Anti-inflammatory IL-4 also induces this neuroprotective phenotype, increasing the production of IGF-1 and lowering production of TNF- $\alpha$ [37]. Furthermore, anti-inflammatory IL-10, although less studied, shows indications of a neuroprotective role on NPC fate [42]. The effects of TGF- $\beta$, on the other hand, are more complicated; some studies show that TGF- $\beta$ decreases proliferation and inhibits neurogenesis, $[47,50]$ while others show a beneficial role of TGF- $\beta$ after brain injury $[48,52]$.

Understanding the role inflammation has on NPC fate is important for diseases such as MS, where the immune system is intricately linked to pathogenesis. Neuroimmune interactions are also essential for understanding other neurodegenerative disorders and for improving the efficacy of stem cell transplantation therapies. Cytokine actions on
NPCs can vary based on the type of disorder and the host tissue [9]. For example, IL- $1 \beta$ specifically plays a role in depression and stressinduced neurodegeneration [12] while Parkinson's and Alzheimer's are characterized by chronic activation of microglia and production of pro-inflammatory cytokines respectively [3]. For a review of the role the immune system plays in certain CNS disorders see [62]. Cytokines are a key factor in controlling the inflammatory environment and could be regulated in order to enhance NPC transplantation [1]. The effect of stem cell treatments will depend not only on the modulation of the endogenous cytokine microenvironment, but also on the type of stem cell transplanted and the area of transplantation [9]. Some inflammation is necessary for repair, although across the board, an excess of inflammation is detrimental $[8,14,63]$. A balance between pro- and anti-inflammatory factors will need to be met in order for neural repair to occur.

The current literature demonstrates that pro-inflammatory and anti-inflammatory cytokines have distinct positive and negative effects on NPC function. This would suggest that the inflammatory response that is the hallmark of the disease MS not only contributes to the destruction of myelin, but may also be critical for repair and regeneration. The suppression of disease activity by future therapeutic agents should take into consideration possible inflammatorymediated repair mechanisms. For example, an up-regulation of antiinflammatory cytokines such as IL-10 could be beneficial in diseases such as MS. In mice with EAE, over-expression of IL-10 in NPCs reduced disease symptoms such as myelin damage, although further studies in humans will need to be conducted [42]. Additionally, NPCs themselves can have effects on the immune system, generating a complex cross-talk that could be influential in NPC therapies [4]. The field of neural stem cell transplantation is progressing rapidly. The role immunomodulatory factors such as cytokines have on NPC fate is just one area that needs to be considered when designing effective stem cell therapies.

\section{Acknowledgements}

We would like to thank Erika Williams and Benjamin Segal for their thoughtful comments and suggestions.

\section{References}

1. Ormerod B, Palmer $T$, Caldwell $M$ (2008) Neurodegeneration and cell replacement. Philos T R Soc B 363: 153-170.

2. Gage F (2002) Neurogenesis in the adult brain. J Neurosci 22: 612-613.

3. Carpentier P, Palmer T (2009) Immune influence on adult neural stem cell regulation and function. Neruon 64: 79-92.

4. Knight J, Hackett C, Breton J, Mao-Draayer Y (2011) Cross-talk between CD4+ T-cells and neural stem/progenitor cells. J Neurol Sci 306: 121-128.

5. Deverman B, Patterson P (2009) Cytokines and CNS development. Neuron 64 61-78.

6. de Araujo E, Mataruna da Silva G, Araujo dos Santos A (2010) Neuronal cell survival: the role of interleukins. Neuroimmunomodulat 1153: 57-64.

7. Szelényi J (2001) Cyokines and the central nervous system. Brain Res Bull 54 329-338.

8. Russo I, Barlati S, Bosetti $F$ (2011) Effects of neuroinflammation on the regenerative capacity of brain stem cells. J Neurochem 116: 947-956.

9. Mathieu P, Battista D, Depino A, Roca V, Graciarena M, et al. (2010) The more you have, the less you get: The functional role of inflammation on neuronal differentiation of endogenous and transplanted neural stem cells in the adult brain. J Neurochem 112: 1368-1385.

10. Molina-Holgado E, Molina-Holgado F (2010) Mending the broken brain neuroimmune interactions in neurogenesis. J Neurochem 114: 1277-1290. 
Citation: Breton J, Mao-Draayer Y (2011) Impact of Cytokines on Neural Stem/Progenitor Cell Fate. J Neurol Neurophysiol S4. doi:10.4172/21559562.S4-001

11. Ben-Hur T, Ben-Menachem O, Furer V, Einstein O, Mizrachi-Kol R, et al (2003) Effects of proinflammatory cytokines on the growth, fate and motility of multipotential neural precursor cells. Mol Cell Neurosci 24: 623-631.

12. Koo J, Duman R (2008) IL-1 $\beta$ is an essential mediator of the antineurogenic and anhedonic effects of stress. P Natl Acad Sci USA 105: 751-756.

13. Wang $\mathrm{X}$, Fu S, Wang $\mathrm{Y}, \mathrm{Yu} \mathrm{P}$, Hu J, et al. (2007) Interleukin -1 $\beta$ mediates proliferation and differentiation of multipotent neural precursor cells through the activation of SAPK/JNK pathway. Mol Cell Neurosci 36: 343-354.

14. Monje M, Toda H, Palmer T (2003) Inflammatory blockade restores adult hippocampal neurogenesis. Science 302: 1760-1765

15. Brenneman, D, Schultzberg M, Bartfai T, Gozes I (1992) Cytokine regulation of neuronal survival. J Neurochem 58: 454-460.

16. Cacci E, Ajmone-Cat M, Anelli T, Biagioni S, Minghetti L (2008) In vitro neuronal and glial differentiation from embryonic or adult neural precursor cells are differently affected by chronic or acute activation of microglia. Glia 56: 412425.

17. Ajmone-Cat M, Cacci, E, Ragazzoni, Y, Minghetti, L, Biagioni S (2010) Progliogenic effect of IL-1 $\alpha$ in the differentiation of embryonic neural precursor cells in vitro. J Neurochem 113: 1060-1072.

18. Gonzalez-Perez O, Quiñones-Hinojosa A, Garcia-Verdugo J (2010) Immunological control of adult neural stem cells. J Stem Cells 5: 23-31.

19. Vallières L, Rivest S (1997) Regulation of the genes encoding interleukin-6, its receptor and gp130 in the rat brain in response to the immune activator lipopolysaccharide and the proinflammatory cytokine interleukin-1 $\beta$. J Neurochem 69: 1668-1683.

20. Vallières L, Campbell I, Gage F, Sawchenko P (2002) Reduced hippocampal neurogenesis in adult transgenic mice with chronic astrocytic production of interleukin-6. J Neurosci 22: 486-492.

21. Johansson S, Price J, Modo M (2008) Effect of inflammatory cytokines on major histocompatability complex expression and differentiation of human neural stem/progenitor cells. Stem Cells 26: 2444-2454

22. Islam O, Gong X, Rose-John S, Heese K (2009) Interleukin-6 and neural stem cells: more than gliogenesis. Mol Biol Cell 20: 188-199.

23. Sarder M, Abe K, Saito H, Nishiyama N (1996) Comparative effect of IL-2 and IL-6 on morphology of cultured hippocampal neurons from fetal rat brain. Brain Res 715: 9-16.

24. Barkho B, Song H, Aimone J, Smrt R, Kuwabara T, et al. (2006) Identification of astrocyte-expressed factors that modulate neural stem/progenitor cell differentiation. Stem Cells Dev 15: 407-421.

25. Tilg H, Dinarello C, Mier J (1997) IL-6 and APPs: anti-inflammatory and immunosuppressive mediators. Immunol Today 18: 128-132.

26. Bauer S (2009) Cytokine Control of Adult Neural Stem Cells. Neuroimmunomodulat 1153: 48-56

27. Iosif R, Ekdahl C, Ahlenius H, Pronk C, Bonde S, et al. (2006) Tumor necrosis factor receptor 1 is a negative regulator of progenitor proliferation in adult hippocampal neurogenesis. J Neurosci 26: 9703-9712.

28. Wu J, Kuo J, Liu Y, Tzeng S (2000) Tumor necrosis factor-alpha modulates the proliferation of neural progenitors in the subventricular/ventricular zone of adult rat brain. Neurosci Lett 292: 203-206.

29. Widera D, Mikenberg I, Elvers M, Kaltschmidt C, Kaltschmidt B (2006) Tumor necrosis factor $\alpha$ triggers proliferation of adult neural stem cells via IKK/NF-KB signalling. BMC Neurosci 7: 64

30. Wong G, Goldshmit Y, Turnley A (2004) Interferon-y but not TNF- $\alpha$ promotes neuronal differentiation and neurite outgrowth of murine adult neural stem cells. Exp Neurol 187: 171-177.

31. Cacci E, Claasen J, Kokaia Z (2005) Microglia-derived tumor necrosis factor-a exaggerates death of newborn hippocampal progenitor cells in vitro. J Neurosci Res 80: 789-797.

32. Liu Y, Lin H, Tzeng S (2005) Tumor necrosis factor- $\alpha$ and interleukin-18 modulate neuronal cell fate in embryonic neural progenitor culture. Brain Res 1054: 152-158

33. Bruce A, Boling W, Kindy M, Peschon J, Kraemer P, et al. (1996) Altered neuronal and microglial responses to excitotoxic and ischemic brain injury in mice lacking TNF receptors. Nat Med 2: 788-794.

34. Beck R, Wasserfall C, Ha G, Cushman J, Huang Z, et al. (2005) Changes in hippocampal IL-15, related cytokines, and neurogenesis in IL-2 deficient mice. Brain Res 1041: 223230

35. Green D, Droin N, Pinkoski M (2003) Activation-induced cell death in T cells Immunol Rev 193: 70-81.

36. Trinchieri G, Kubin M, Bellone G, Cassatella M (1993) Cytokine cross-talk between phagocytic cells and lymphocytes: relevance for differentiation/ proliferation of phagocytic cells and regulation of adaptive immunity. J Cell Biochem 53: 301-308.

37. Butovsky O, Ziv Y, Schwartz A, Landa G, Talpalar A, Pluchino S, et al. (2006) Microglia activated by IL-4 of IFN-y differentially induce neurogenesis and oligodendrogenesis from adult stem/progenitor cells. Mol Cell Neurosci 31 : 149-160.

38. Martino G, Pluchino S (2006) The therapeutic potential of neural stem cells. Nat Rev Neurosci 7: 395-406.

39. Mäkela J, Koivuniemi R, Korhonen L, Lindholm D (2010) Interferon-y produced by microglia and the neuropeptide PACAP have opposite effects on the viability of neural progenitor cells. PLOS ONE 5: 6.

40. Song J, Wang C, Song D, Wang P, Shuaib A, et al (2005) Interferon y induces neurite outgrowth by up-regulation of p35 neuron-specific cyclin-dependent kinase 5 activator via activation of ERK1/2 pathway. J Biol Chem 280: 1289612901.

41. Sloan D, Wood M, Charlton H (1991) The immune response to intracerebral neural grafts. Trends Neurosci 14: 341-346

42. Yang J, Jiang Z, Fitzgerald D, Ma C, Yu S (2009) Adult neural stem cell expressing IL-10 confer potent immunomodulation and remeyelination in experimental autoimmune encephalitis. J Clin Invest 119: 3678-3691.

43. Molina-Holgado E, Vela J, Arévalo-Martín A, Guaza C (2001). LPS/IFN-Y cytotoxicity in oligodendroglial cells: role of nitric oxide and protection by the anti-inflammatory cytokine IL-10. Euro J Neurosci 13: 493-502.

44. Pluchino S, Martino G (2005) The therapeutic use of stem cells for myelin repair in autoimmune demyelinating disorders. J Neurol Sci 233: 117-119.

45. Guan Y, Jiang Z, Ciric B, Rostami A, Zhang G (2008) Upregulation of chemokine receptor expression by IL-10/IL-4 in adult neural stem cells. Exp Mol Pathol 85 232-236.

46. Nolan Y, Maher F, Martin D, Clarke R, Brady M, et al. (2005) Role of interluekin-4 in regulation of age-related inflammatory changes in the hippocampus. $\mathrm{J}$ Bio Chem 280: 9354-9362.

47. Buckwalter M, Yamane M, Coleman B, Ormerod B, Chin J, et al. (2006) Chronically increased transforming growth factor- $\beta 1$ strongly inhibits hippocampal neurogenesis in aged mice. Am J Pathol 169: 154-164.

48. Battista D, Ferrari C, Gage F, Pitossi, F (2006) Neurogenic niche modulation by activated microglia: transforming growth factor $\beta$ increases neurogenesis in the adult dentate gyrus. Eur J Neurosci 23: 83-93.

49. Montaron M, Petry K, Rodriguez J, Marinelli M, Aurousseau C, et al. (1999) Adrenalectomy increases neurogenesis but not PSA-NCAM expression in aged dentate gyrus. Eur J Neurosci 11: 1479-1485.

50. Sloviter R, Valiquette G, Abrams G, Ronk E, Sollas A, et al. (1989). Selective loss of hippocampal granule cells in the mature rat brain after adrenalectomy. Science 243: 535-538.

51. Wachs F, Winner B, Couillard-Despres S, Schiller T, Aigner R, et al. (2006) Transforming growth factor- $\beta 1$ is a negative modulator of adult neurogenesis. $J$ Neuropath Exp Neur 65: 358-370.

52. Ma M, Ma Y, Yi X, Guo R, Zhu W (2008) Intranasal delivery of transforming growth factor-beta 1 in mice after stroke reduces infarct volume and increases neurogenesis in the subventricular zone. BMC Neurosci 9: 117.

53. Benveniste E, Tang L, Law R (1995) Differential regulation of astrocyte TNFalpha expression by the cytokines TGF- beta, IL-6 and IL-10. Int J Dev Neurosc 13: $341-349$

54. Brionne T, Tesseur I, Masliah E, Wyss-Coray T (2003) Loss of TGF- $\beta 1$ leads to increased neuronal cell death and microgliosis in mouse brain. Neuron 40 : 1133-1145. 
Citation: Breton J, Mao-Draayer Y (2011) Impact of Cytokines on Neural Stem/Progenitor Cell Fate. J Neurol Neurophysiol S4. doi:10.4172/21559562.S4-001

55. Lenzlinger $P$, Morganti-Kossmann M, Laurer H, Mclntosh T (2001) The duality of the inflammatory response to traumatic brain injury. Mol Neurobiol. 24: 169181

56. Huang Y, Cheng S, Chueh S, Tsai Y, Liou N, et al. (2009) Effects of interleukin-15 on neuronal differentiation of neural stem cells. Brain Res 1304 38-48.

57. Gómez-Nicola D, Valle-Argos B, Pallas-Bazarra N, Nieto-Sampedro M (2011) Interleukin-15 regulates proliferation and self-renewal of adult neural stem cells. Mol Biol Cell 22: 1960-1970.

58. Matus A (1988) Microtubule-associated proteins: their potential role in determining neuronal morphology. Annu Rev Neurosci 11: 29-44.

59. Campbell J, Cook G, Robertson S, Fraser A, Boyd K, et al. (2001). Suppression of IL-2 induced T cell proliferation and phosphorylation of STAT3 and STAT5 by tumor-derived TGF $\beta$ is reversed by IL-15. J Immunol 167: 553-561.

60. Moors M, Vudattu N, Abel J, Krämer U, Rane L, et al. (2010) Interleukin-7 (IL-7) and IL-7 splice variants affect differentiation of human neural progenitor cells. Genes Immun 11: 11-20.

61. Araujo D, Cotman C (1993) Trophic effects of interleukin-4, -7 and -8 on hippocampal neuronal cultures: potential involvement of glial-derived factors. Brain Res 600: 49-55.

62. Graber J, Dhib-Jalbut S (2009) Protective autoimmunity in the nervous system. Pharmacol Therapeut 121: 147-159.

63. Ekdahl C, Claasen J, Bonde S, Kokaia Z, Lindvall O (2003) Inflammation is detrimental for neurogenesis in adult brain. P Natl Acad Sci USA 100: 1363213637.
This article was originally published in a special issue, Neurorehabilitation \& Neural Repair handled by Editor(s). Dr. Hsinlin Thomas Cheng, University of Michigan, USA 